\title{
TERRITORIALIDADE E BIOGRAFIA: AO REDOR DE TIA EVA
}

TERRITORIALITY AND BIOGRAPHY: AROUND AUNT EVA

\author{
TERRITORIALIDAD Y BIOGRAFÍA: AL REDOR DE TIA EVA
}

Myleide Meneses Oliveira Machado ${ }^{1}$

Josemar de Campos Maciel$^{2}$

\begin{abstract}
Resumo: Na investigação da história das comunidades quilombolas no Brasil, urge redimensionar conceitos como "identidade" e "territorialidade" mostrando que as comunidades produzem ressignificações, em suas relações com o espaço num sistema de representação político territorial. Este artigo focaliza a Comunidade Quilombola São Benedito, no Estado de Mato Grosso do Sul, cidade de Campo Grande, formada no início do século XX. O artigo explora teoricamente o auto-reconhecimento e identificação da Comunidade, com formas próprias de organização social, ocupando e usando territórios e recursos como condição para sua ancestral reprodução cultural, social, religiosa e econômica, negociando conhecimentos, inovações e práticas com a tradição e na sua inserção no município.
\end{abstract}

Palavras-Chave: Comunidade. Territorialidade. Quilombolas.

\begin{abstract}
When dealing with "quilombola" communities, descendants from slaves in Brazil, it is urgent to reframe concepts such as "identity" and "territoriality", showing that they can produce new meanings through establishing relationships with their circling space, embedded as they are into a politico-territorial system. This paper explores the life and identities in the "São Benedito quilombola Community", in the state of Maro Grosso do Sul, city of Campo Grande, dated from the beginnings of the 20th century. One explores theoretically the fact that the community recognizes and identifies herself as such, that is, building her own forms of social organization, occupying and making use of territory and natural resources as a condition for her endurance, negociating their tradition with the surrounding modernity of Campo Grande, in South Mato Grosso.
\end{abstract}

Keywords: Community. Territoriality. Quilombolas.

Resumen: En la investigación de la historia de las comunidades quilombolas en Brasil, urge redimensionar conceptos como "identidad" y "territorialidad" mostrando que las comunidades producen resignificaciones, en sus relaciones con el espacio en un sistema de representación

\footnotetext{
${ }^{1}$ Professora da Secretaria Estadual de Mato Grosso do Sul e Secretaria Municipal de Dourados nas disciplinas de História e Filosofia. Mestranda do Programa de Pós-Graduação em História (PPGH/UFGD), Linha de Pesquisa Fronteiras, Identidades e Representações. E-mail: mylarf.machado@gmail.com.

${ }^{2}$ Doutor em Psicologia pela Pontifícia Universidade Católica de Campinas (2004). Atualmente, professor na Universidade Católica Dom Bosco.
} 
político territorial. Este artículo se centra en la Comunidad Quilombola San Benedito, en el Estado de Mato Grosso del Sur, ciudad de Campo Grande, formada a principios del siglo XX. El artículo explora teoricamente el auto-reconocimiento y identificación de la Comunidad, con formas propias de organización social, ocupando y usando territorios y recursos como condición para su ancestral reproducción cultural, social, religiosa y económica, negociando conocimientos, innovaciones y prácticas con la tradición y en su inserción en el municipio.

Palabras clave: Comunidad. Territorialidad. Quilombolas.

\section{Introdução: Ser e dizer-se negro.}

As sociedades humanas precisam de uma referência espacial como condição elementar para projetar-se e pensar-se, refletindo acerca de questões de seu próprio interesse - tanto cientificamente quanto através da construção de representações e celebrações culturalmente qualificadas. O território é o local em que uma sociedade constrói suas redes de significados e pertencimentos, reproduzindo-se de acordo com sua gramática cultural. Toda sociedade humana necessita de um espaço que lhe forneça elementos para um estabelecimento adequado ao seu sistema sociocultural e que lhe permita "ordenar, a partir de um ponto, o universo circundante". Para Milton Santos (1978, p 67), o espaço social é coextensivo ao espaço humano, lugar de vida e trabalho: morada ds seres humanos, em arranjos dinâmicos. O espaço geográfico é organizado a partir da vida em sociedade. Cada sociedade, por sua vez, produz seu espaço historicamente circunscrito como lugar de sua própria reprodução. A utilização do território pelos grupos humanos "cria o espaço" (SANTOS, 1978, p. 67); imutável em seus limites e mutável ao longo da história, o território antecede o espaço. O território de uma sociedade comporta elementos que fazem parte da construção da sua identidade e da formação como parte integrante do mundo.

A discussão, neste estudo, sobre "ser negro" não busca a produção do encapsulamento desse "Ser" numa suposta essência. Aqui, Ser negro é pensado a partir da identidade social como construção, seletividade e teia de relações. Entendemos que, abordando o "Ser" dessa forma, evitamos pensá-lo de maneira estática. É nessa perspectiva relacional que desenvolvemos a discussão sobre o "ser negro" enquanto indicador de uma "identidade 
negra" em movimento. Em relação à "raça" e ao discurso da mestiçagem, estamos nos apoiando num referencial teórico que entende tais realidades como historicamente determinadas e constantemente atualizadas nas práticas sociais.

Dessa forma, portanto, pretendemos afastar da discussão uma visão monolítica da elaboração de "identidades negras", assim alcançando e pontuando ações sociais que os identificam e determinam com sua formação como cidadãos ativos. Para melhor delimitar o sentido em que está sendo empregada a ideia do "Ser" enquanto "identidade" neste artigo, partimos da premissa, construída através de um jogo dialético entre semelhança e diferença. Essa definição implica que as "identidades" não são elaboradas isoladamente, mas a sua produção acontece com base na percepção da alteridade e nas relações estabelecidas entre os grupos. Quem se define como "negro", em um dado contexto, pode não assumir a mesma auto-afirmação em outro contexto e situação social (SANSONE, 2004). Portanto, a reflexão sobre "identidade" pressupõe sempre uma contextualização densa das especificidades das relações sociais vividas pelos indivíduos envolvidos.

\section{Comunidade Quilombola Tia Eva}

Este artigo analisará a Comunidade Quilombola Tia Eva, no estado de Mato Grosso do Sul, na cidade de Campo Grande, formada no início do século XX. Em sentido geral objetivase mostrar o sentido em que a Comunidade se reconhece como tal. Esse sentido originário desdobra-se em diversas dinâmicas. Cumpre mostrar que a Comunidade possui formas próprias de organização social, que ocupa e usa territórios e recursos naturais como condição para sua reprodução cultural, social, religiosa, ancestral e econômica, utilizando conhecimentos, inovações e práticas gerados e transmitidos pela tradição dentro do município de Campo Grande e do estado Mato Grosso do Sul.

Os problemas acerca das crises de identidade originadas por diversas fontes de pressão, seja individual, coletiva ou social, geram consequências graves para os indivíduos. As questões pertinentes à cultura, bem como a constituição das identidades individuais e coletivas, costumam intensificar-se em momentos de crise, impactando nas relações de poder 
estabelecidas por um sistema de vida e territorialidade que combina condições de subsistência com padrões e valores morais, comportamentais e de crenças.

Conceituar as identidades a partir das relações de poder estabelecidas pelas sociedades, no contexto das atuais crises da modernidade pode permitir compreender e analisar está identidade constituída através do outro. Os sujeitos vivem em um sistema multicultural, convivem às vezes de forma dolorosa com suas múltiplas identidades, muitas vezes fragmentadas e deterioradas.

Dessa forma, essa identidade fracionada, complicada ulteriormente por eventuais crises de referências culturais, marca ainda mais os indivíduos, externa e internamente. É fundamental para o sujeito construir uma consciência do espaço que ocupa, participativo e presente na sua construção sócio histórica. Dessa forma, é importante substantivar a coexistência de várias culturas nos diversos ambientes e grupos sociais. É a partir disso que se torna possível o sujeito refletir sobre si mesmo e o outro. A partir daí, ele pode se questionar como indivíduo, com diferentes graus de consciência, redefinindo seu modo de estar presente no mundo, tecendo então sua identidade em suas relações e na produção da sua intimidade. $\mathrm{O}$ trabalho acerca dessas questões contribui no sentido de promover a reflexão sobre essa temática que se apresenta importante para a constituição do sujeito enquanto individuo construtor de suas relações sócio históricas.

Antes e depois da abolição da escravatura o território brasileiro esteve marcado pela presença de comunidades negras que ainda hoje resistem, buscando a manutenção ou reconquista de seus territórios, diante de pressões oriundas de diversas fontes, ligadas ao processo de territorialização de um Estado moderno que não resolveu as perguntas básicas sobre seus modelos de desenvolvimento. As pressões partem de latifundiários em busca de mais espaço para seus monopólios, de especuladores imobiliários em busca de terrenos que lhes propiciem aumento de lucro, até mesmo do poder público em crise de representação, em busca de afirmação de seu próprio autoritarismo. As vidas dos libertos e seus descendentes negros estão presentes, como sabemos, nos registros da memória e da oralidade, a perene forma de expressão humana. Cada ex escravo e afrodescendente traz consigo um leque de histórias repletas de momentos de alegria, dor, esperanças que entremearam sua história pessoal à história social abrangente. Por isso, além de recorrer à documentação escrita, 
contamos com relatos orais. Desta forma, o processo de territorialização quilombola constituise muitas vezes, na luta para continuar a existir, na reinvenção de uma identidade política portadora de direitos, informada por uma memória ancestral.

A memória, neste sentido, tem grande importância, visto que em geral se trata de comunidades iletradas, de forte tradição oral e que encontram na reinvenção de suas identidades uma oportunidade de recriação historiográfica. Importante ressaltar que, nada substitui a experiência transmitida de boca em boca, seja do viajante que carrega em sua bagagem uma variedade de histórias para contar, seja daquele que nunca saiu de seu país e carrega, por isso, uma única história - o saber de sua geração deve ter um valor incalculável.

A vida dos negros no pós - abolição desenrolou - se em meio a um a série de acontecimentos adversos. Não houve incentivos governamentais para apoiar a sua vida liberta, perpetuando-se os estereótipos negativos remanescentes da escravidão que os desvalorizava da condição de trabalhadores preferenciais e quase únicos por tantos séculos. Havia, ademais, no Brasil, um processo intenso de migração que pode ser entendido como resultado, de uma forma voluntária ou compulsória, da saída definitiva de determinado espaço, região ou pais, em busca de outras áreas ou limites justificada pelas mudanças, prevalecendo os motivos e interesses dos grupos econômicos e sociais dominantes. É importante situarmos a função, aqui, da reflexão histórica, sabendo que a identidade é uma construção social, de uma certa maneira sempre acontecendo no quadro de uma relação dialógica com o outro compreendendo a relação entre muitas memórias e outras histórias. Não se trata apenas de um movimento retrospectivo, mas aponta para um campo de tensões e disputas em torno do direito ao passado.

A pesquisa sobre a constituição da identidade cultural no ambiente da comunidade Quilombola Tia Eva exigiu conceituar os termos cultura, identidade, territorialidade a relação dos sujeitos diante desses fatos, mas para que isso acontecesse foi necessário recorrer à interação direta com a Comunidade, convivendo com ela e entrevistando seus membros através de técnicas remissivas de História Oral. Ou seja, o contato foi sendo feito diretamente, e os próprios membros indicavam outras pessoas que poderiam contribuir. Atenção especial foi dada a membros reputados como mais antigos, detentores de autoridade e de narrativas que os outros consideravam importantes. 
Através dos depoimentos possibilitou-se identificar a forma como as questões que gravitam ao redor da identidade estão presentes na vida e na forma de pensar e trabalhar dos sujeitos que também constituem a cultura no Estado de Mato Grosso do Sul. Ainda foi possível revisitar o papel da comunidade Quilombola frente a essas questões, considerando que ela recebeu influências culturais de diversos lugares, sabendo que a construção da história sul-mato-grossense se reveste também de uma relação de domínio, de uma identidade "montada" e de interesses diversos, sobretudo, uma elite dominadora e opressora que tenta sistematicamente apagar esta comunidade e as suas narrativas.

\section{Território, identidade e cultura}

O território pode ser considerado como delimitado, às vezes tecido, às vezes esgarçado pela fricção de relações de poder que envolvem uma gama muito grande de atores que territorializam suas ações no cenário do passar do tempo. O espaço, dessa maneira, é construído processualmente e contém uma estrutura organizada por formas e funções que podem mudar historicamente em consonância com cada sociedade. Os processos sociais e tecnológicos modelam o espaço de acordo com os sistemas incorporados e estes vão dando lugar a outros sistemas que gerarão uma nova organização do espaço. Este é reconstruído constantemente, na história. Os sistemas de fluxo também são elementos que desempenham importante papel na organização espacial e isso revela a ligação e a preocupação com os objetos e com as ações, numa abordagem continuadamente histórica.

A cada momento histórico, cada elemento muda seu papel, sua posição no sistema espacial e o valor de cada um deve ser tomado da sua relação com os demais elementos. Isso significa que as variáveis do espaço mudam no movimento do tempo histórico. A organização do espaço pode ser definida como o resultado do equilíbrio entre os fatores de dispersão e de concentração em um dado momento na história do espaço. Para Santos (1985, p 122), o espaço é o resultado da produção, uma decorrência de sua história, mais precisamente, da história dos processos produtivos impostos ao espaço pela sociedade.

Nesse contexto é importante salientar que o conceito de cultura, para o nosso objeto, tem relação direta com processos de estabelecimento de relações de trabalho, na consolidação 
do capitalismo real. Com isso, formava-se uma nova sociedade, diante de um novo modo de ver e viver o mundo. As mudanças nas relações sociais e culturais foram significativas, o que acarretou uma certa fusão de significações. Vive-se um momento de profunda crise do modelo moderno de ser e de existir; porém, não existe uma consciência dessa ruptura, o que indica pouco entendimento acerca dessa mudança.

Anteriormente a essa intensa crise, marcada pela urbanização e pelas alterações significativas das relações de trabalho, atravessadas pela chaga do comércio de escravos, a experiência da cultura era bastante conectada ao engajamento, ideologias, lutas políticas e sociais. Vivia-se uma época em que segmentos da sociedade se organizavam em prol de uma luta real - o que significava buscar uma identidade. A partir da década de 1960 e 70 materializa-se a crise, deixando a ideia de cultura a valência da crítica à sociedade, tornandose mais um conjunto de objetos patrimonializados e a serviço das classes dominantes, ao lado dos veículos que sustentam parte da sociedade (EAGLETON, 2005, p. 87). Nesse sentido, ao longo do século XX nota-se como o processo de discussão da cultura sofre sucessivas ondas de elitização, ficando populações que dependem, por exemplo, da oralidade, curcunscritas à margem da chamada "grande cultura".

Etimologicamente cultura é uma palavra derivada de "colere” (CHAUÍ, 2000, p. 374), verbo latino que tem sentido de cultivar, criar, tomar conta e cuidar. Nesse sentido, entendese que a natureza, experiência básica do ser humano, necessita de cuidado e de um cultivo que parte da ação e da vontade do homem de agir sobre ela. Assim, a cultura aparece, em sua origem, como o reflexo das ações humanas livremente escolhidas, dando significado e valor ao ambiente. De certo modo, cultura e natureza interagem de forma mutuamente fecunda, gerando a narrativa que tenta dar conta de todo o processo, a história, criada e contada pelo homem.

Para Zygmunt Bauman (2005, p. 35), pode-se dizer que identidade é um processo de construção permanente em contínua transformação, intangível e ambivalente, de invenção e reinvenção das histórias pessoais e coletivas. Stuart Hall e seu grupo avançam na discussão, partindo do pressuposto que as velhas identidades estão em declínio, indagando-se pelo significado das novas identidades, fragmentadas pela complexa relação indivíduo e sociedade, o que constitui a chamada crise identitária. Entretanto, o processo de transformação ocorre por

Fronteiras: Revista de História | Dourados, MS | v. 19 | n. 33 | p. 147 - 169 | Jan. / Jun. 2017 
vezes de forma constante numa velocidade intensa que também pode causar angustia e dor, o que gera então as diversas crises de identificação. Stuart Hall complementará essa ideia ao sugerir que em momentos de crise o indivíduo, com diferentes graus de consciência, busca redefinir seu modo de estar presente no mundo, procurando encontrar uma identidade para si próprio e para os outros.

Muitas vezes essa identidade encontra-se perdida, fragmentada, deteriorada, coincidindo com a ideia de que as identidades nas sociedades industriais e além, estão realmente em crise. Os debates acerca da identidade e de suas repercussões têm sido marcantes, situando a discussão por diferentes prismas. Isso ocorre em parte como sintoma da crise atual em que o indivíduo experimenta o pertencimento como dissolução e tensão, mais do que como um espaço construído a partir de um significado. Assim, submetidas ao cipoal das convenções sociais, as identidades se perdem pela ausência de entendimento e compreensão da sua real necessidade de existir. De certo modo, o diálogo com a discussão aqui apenas esboçada contribui no entendimento do que vem a ser cultura e identidade, de que forma se deve compreende-las e assim partir para um debate embasado em conceitos reais.

Ora, isso nos leva a tentar mais um passo, questionando num primeiro momento o que é identidade cultural, sobretudo a partir da sugestão de Hall de que deve-se discutir uma identidade étnico-cultural, compreendendo que dividimos espaços com sujeitos de diferentes culturas e etnias, imbuídos de seus valores e crenças, e que compartilham suas experiências de forma nada problemática. Se as culturas são dinâmicas e estão em constante transformação, e se sabemos que os sujeitos se constituem nas relações com outros, isso ilumina o que já foi visto anteriormente. Ou seja, estas relações se dão a partir das ações estritamente humanas que necessitam de intermediação, seja por meio da técnica material, seja por meio de ferramentas semióticas, elaborando as linhas de significação, como no caso da pesquisa.

O Estudo sobre as identidades culturais torna-se mais importante, quanto mais se observa o sentimento de insegurança em que mergulha o sujeito que vivencia o seu cotidiano atualmente. Desenvolvemos nosso trabalho em geral refletindo sobre a necessidade de construir uma identidade definida, que provê o sentimento de segurança. É necessário que o indivíduo se reconheça para que assim ele possa reconhecer suas próprias necessidades e então reconhecer as necessidades do outro. Quando negamos ou não reconhecemos 
determinada identidade, corremos o risco de acabar tendo a identificação atribuída ou designada por outro, estereotipada e possivelmente estigmatizada. Essa necessidade de pertencimento, de aceitação, essa busca incessante por uma identidade definida causa angústia aos indivíduos, angústia inerente ao sujeito e que ocasiona as crises de identidade, tão presentes nas sociedades de hoje. A sociedade se configura a partir de um mundo superrecriado pelos signos, desfazendo princípios, regras e valores, tornando-se ambígua. O sujeito presente nessa sociedade é multicultural, multifacetado, superficial, porque as discussões na sociedade inflacionada pelas batalhas de signos são fragmentadas e superficiais. As culturas descentradas presentes na modernidade tardia geram um esvaziamento ideológico nas experiências culturais. Aparece uma ideia de cultura representada de várias formas, seus conceitos e suas significações foram fragmentadas. Tudo é aceito como cultura num mundo globalizado e condensado de recriações e apropriações de signos e significados. O que acaba remetendo ao oposto. Se ela tudo pervade, então corre o risco de perder o seu valor de face.

A "identidade negra" é um valor disputado em conflitos sociais e intergrupais. A sua formação pressupõe um trabalho de organização do grupo ou sociedade. Esse trabalho de organização é feito através da reconstrução, pelo grupo, de sua própria história. A reconstrução da história do grupo vai acontecer de acordo com as características históricas e sociais, com as quais se relaciona. Desse modo, a "identidade negra" é inteligível apenas no interior do seu contexto cultural. Assim, o conceito de "identidade negra", encaminha-se no sentido de entendê-la como uma realidade dinâmica e contextual. Isso pode ser sintetizado na argumentação de Sansone:

[...] A identidade negra, como todas as etnicidades, é relacional e contingente. Branco e negro existem, em larga medida, em relação um aos outros; as "diferenças" entre negros e brancos variam conforme o contexto e precisam ser definidas em relação a sistemas nacionais específicos e a hierarquias globais de poder, que foram legitimados em termos raciais e que legitimam os termos raciais (SANSONE, 2003, p. 24).

Assim, a "identidade negra" não acontece como representação genérica da essência do significado de ser "negro". Mas é interpretada como uma construção intersubjetiva, determinada pelo contexto social e pelos significados das experiências interpessoais referentes 
ao processo de auto-afirmação das pessoas. Portanto, a África e as ancestralidades africanas são buscadas pelos que reivindicam alguma forma de identidade negra, também, no sentido de afirmação social perante o contexto local, e como uma forma de manter laços simbólicos com o continente africano.

É relevante também destacar a discussão sobre a diáspora negra para o Novo Mundo e todo o processo de influências que as ideia e símbolos associados à África exerceram e exercem sobres os processos de elaboração de "identidades negras" fora do continente africano (GILROY, 2001, p 356). Neste caso, a família constitui um espaço no qual os estereótipos negativos relacionados ao "negro" são também reproduzidos. Isso até mesmo entre as famílias "negras", tal como relatado nas falas acima. As atitudes racistas presenciadas na esfera familiar devem configurar obstáculos à formação de "identidades negras" (GUIMARÃES, 1999, p 238). Mas, os processos de construção de "identidades negras" não se limitam apenas à esfera familiar. Como alguns evidenciam, as "identidades negras" são elaboradas através das experiências pessoais vividas nos variados espaços sociais de interação. Mesmo mecanismos de construção ou reprodução do racismo, inseridos no próprio seio familiar, não anulam os processos de construção da "identidade negra" entre determinados membros da família. Outro ponto importante que acontece no contexto da discussão diz respeito à resistência e ao repúdio da imagem negativa do "negro", construída e reproduzida socialmente. As "identidades negras", o seu "ser negro", foram se constituindo mais pela percepção do olhar diferenciado do que pela constatação da própria "cor" da pele. É relevante destacar as ideias de sofrimento e humilhação devido ao estigma da "cor", evidenciadas em tantos relatos.

Usar exclusivamente a expressão "ser negro" como forma de se auto-afirmar, não limita o fenômeno da negritude ou da identidade apenas a um grupo étnico e marginalizado. Apesar do significado de tal expressão ter um caráter subjetivo, existem alguns aspectos comuns na forma como se reportaram as "identidades negras". Um deles diz respeito ao valor que a África possui para o significado de "ser negro". De modo geral, a África apresenta-se, para os descendentes, como um banco de referenciais simbólicos norteadores do significado das suas representações. Um outro elemento colocado refere-se à ênfase dada à miscigenação racial e cultural. Para os descendentes, a mistura das "raças" expressa às especificidades do 
racismo brasileiro e os constituem como "negros misturados". Ser negro "misturado" não enfraquece as "identidades negras", mas revela, sobretudo, particularidades de tais formas de auto-afirmação. Isso porque, mesmo observando que não existe "negro" puro no Brasil, eles não deixam de evidenciar o orgulho e o valor de suas "identidades negras".

Também os aspectos fenotípicos foram destacados como importantes para as autoafirmações, principalmente o cabelo, o formato do nariz e a "cor" da pele. Ademais, percebemos que entre os descendentes o significado da expressão "negro" expressa termos de resistência contra o preconceito racial, uma vez que esse preconceito impõe a necessidade de se pensar como diferente. Portanto, esses são aspectos que foram recorrentes nas maneiras dos descendentes afirmarem um "ser negro" como "identidades negras" oriundo da vivência e contato com as diferenças.

Destacamos ainda a importância de um olhar crítico referente às identidades constituídas em uma Comunidade Quilombola inserida numa cidade que se constituiu a partir de uma relação de poder, marcada pela marginalização e exclusão desta etnia. Foi necessário um breve resgate histórico acerca da formação do Estado para que pudéssemos compreender como as relações sociais foram se estabelecendo no arco diacrônico. Evidenciamos o processo de aculturação que os nativos sofreram quando da chegada do europeu na região, bem como a nova identidade que se constitui a partir desse episódio. Observamos que a história de Mato Grosso do Sul tem presente em seu processo histórico uma relação de domínio com o europeu e posteriormente com os grupos dominantes no Estado, constituindo assim as relações de poder em Mato Grosso do Sul. Nesse sentido nos preocupamos em saber como a escola se coloca diante dessas questões, observando através da pesquisa que o ambiente escolar reproduz na prática o discurso hegemônico, e que, portanto, não estabelece uma relação democrática tão presente nos discursos sociais. A contribuição dos relatos orais, bem como a análise de fontes e referências vivenciais contribuiu no sentido de confrontarmos o discurso e a prática no ambiente da comunidade. Dessa forma, o que evidenciamos a partir da análise desse material foi certa insatisfação acerca da identidade construída do sujeito cercado um sentimento de força e vontade de mudança e da reconstrução de uma nova identidade, que se reproduz na forma de comportamento das novas gerações. 


\section{Comunidade Quilombola Tia Eva: da biografia}

A história da comunidade se confunde com a própria história de Tia Eva. Escrava nascida em Mineiros, Goiás, foi batizada como Eva Maria de Jesus. Casada por duas vezes, Eva Maria teve três filhas: Joana, Lázara e Sebastiana. Em 1887, aos 49 anos, Tia Eva obteve sua carta de alforria, saiu de Goiás em 1905, chegando a Campos de Vacaria, hoje, Campo Grande, onde trabalhou como lavadeira, parteira, cozinheira, curandeira e benzedeira. Sabia ler e escrever e, sendo procurada por inúmeras pessoas, foi se tornando referência na comunidade, o que lhe rendeu alguns benefícios financeiros. Até que em 1910, adquiriu uma terra de oito hectares que lhe custou 85 mil réis. Ali residem atualmente seus descendentes. Foi idealizada como uma liderança religiosa na época, pois trazia consigo a missão de cumprir uma promessa, a de construir a igrejinha de São Benedito, quando alcançasse a cura de uma enfermidade na perna, e ali fixaria residência. A fundadora da comunidade faleceu em 1926, e antes de morrer pediu a seus descendentes que não deixassem de rezar ao seu santo. A promessa continua a ser cumprida até hoje. (SALEM, 1999, p. 14).

A importância da comunidade Quilombola Tia Eva se concretiza no tombamento da Igreja de São Benedito, reconhecida pelo Poder Público da cidade de Campo Grande, Mato Grosso do Sul. Como parte do "Patrimônio Público Estadual e Municipal", a igrejinha de São Benedito, assim como sua festa, arregimenta continuamente muitos fiéis, uns prestando suas devoções a São Benedito e outros, à tia Eva. Com o passar dos anos, diversas pessoas têm creditado certos milagres à tia Eva. A fama de milagreira, que se iniciou quando ela era parteira, curandeira e benzedeira, foi aumentando, principalmente após o seu falecimento em 1926. O espaço que os moradores de Campo Grande antes identificavam como de São Benedito hoje é reconhecido por muitos como o de tia Eva, ou comunidade Tia Eva. (SALEM, 1999, p.15).

\section{...à Territorialidade e identidade Quilombola}

No espaço do quilombo, o negro buscou reconstruir sua identidade. Contudo, foi necessário construi-la ao redor da unidade física, ou seja, do sentimento de possuir um espaço 
próprio, presente nesses refúgios, de conservação das raízes e preservação da sua memória. A historicidade quilombola possui fortes traços característicos que são relacionados aos traços estruturais do sistema escravocrata que foi vigente no Brasil e em alguns países da América, por alguns séculos, além de elementos de reação, na busca da liberdade (FALCÃO, 2011, p. 43). No entanto, estudos mostraram que as comunidades de quilombo se constituíram a partir de uma diversidade de processos, o que modificou toda a construção histórica acerca dos mesmos. Estes passaram, com o tempo, a relacionar-se com estruturas que iam além das fugas, englobando também as heranças, doações, recebimentos de terras como pagamento de serviços prestados ao Estado, até à simples permanência nas terras que ocupavam e cultivavam no interior de grandes propriedades, ou à compra de terras, tanto durante a vigência do sistema escravocrata quanto após a abolição (ARRUTI, 2007, p 17). Todo esse contexto representa a dinâmica histórica que desencadeou a criação dos quilombos e a sua representação social, demográfica, econômica, cultural ainda vigente.

As composições para o conceito de quilombo e da identidade quilombola vão além da cor da pele e identidade biológica (FALCÃO, 2011, p 81), partindo de diversas ordens: a fuga, o isolamento social, a diversidade étnica, a mobilização e luta política, o reconhecimento social e cultural. Essas composições são expostas através das relações feitas por Alvarez, (2011, p. 82).

[...] quilombos não são homogêneos, não são puros, não se caracterizam apenas por uma marcada tradição oral e apresentam às vezes uma amnésia estrutural que apaga as lembranças da época da escravidão. Pelo contrário, os quilombos são plurais, híbridos [...].

Em linhas gerais, os quilombos consistem em grupos que desenvolveram práticas de resistência na manutenção e reprodução de modos de vida característicos de um determinado lugar. São grupos sociais cuja identidade étnica os distingue do restante da sociedade (BOSI, 2007, p. 308). Dessa forma, como afirmam Falcão e colegas (2011, p. 12) "os quilombolas de ontem e de hoje sempre se constituíram como tais a partir de complexas teias de relações". O que nos leva a reconstrução do termo quilombola e de suas características é o sentido que os quilombos a partir de uma base histórica, porém, algumas comunidades apresentam 
estruturações, modos, costumes, valores e práticas corporais que são singulares e característicos do local onde se situam - tanto do suposto local de origem quanto destino.

No seio dessa diversidade, existem ainda comunidades urbanas, que estão situadas próximas ou dentro de cidades, como é o caso da comunidade objeto deste estudo, a Comunidade Quilombola Tia Eva, num movimentado entroncamento de bairros de Campo Grande, MS. Tais comunidades apresentam uma forma singular de se relacionar com a terra, com a natureza, com o próximo, com a coletividade, com o trabalho, além da valorização dos traços culturais e da persistência na luta por território e reconhecimento. Pensar a vida em comunidades nos leva a relacionar à vida compartilhada e instituída a partir de interações diretas entre os indivíduos. Portanto, as relações corporais e as relações com o meio social e com a natureza estão fortemente representadas nas expressões corporais e cotidianas dos sujeitos que compõem aquele meio social.

As relações sociais que se refazem no contexto das práticas corporais atravessam muitas dimensões da cultura local, como os rituais que expressam as normas, os conhecimentos e os valores culturais, exprimindo também os corpos dos quilombolas e seus movimentos. Contudo, as práticas corporais possuem sentidos e significados que são determinados socialmente. Se compreendemos a cultura como sendo um processo dinâmico e que se configura como sistema simbólico orientando as representações em diferentes sociedades, fica claro que a articulação se dá através das relações e interações dos sujeitos entre si e com o seu meio. E assim, acontece o ato em que os sujeitos são agentes sociais que atuam, relacionam, compõem e transformam o ambiente.

As representações coletivas em uma dimensão social, cultural e histórica são compostas por símbolos. As lembranças às quais os atores sociais recorrem para entender o passado e (res)significar o presente representam a memória, as experiências de vida, momentos, fatos, pessoas e objetos. E a memória, em diversos momentos, expande-se para a coletividade (CHAUÍ, 2008, p. 65). Não se detém na individualidade, pois além desse caráter pessoal possui um caráter coletivo. A memória passa ser a reconstrução do passado, e este não pode se modificar, mas as interpretações a respeito dele é que variam de sujeito para sujeito. O movimento histórico que acontece com a memória reflete uma propriedade dinâmica do passado, ligando a memória individual e a memória coletiva. 
A memória é capaz de tecer a identidade. A partir dos relatos e histórias contadas portanto, do recorte da oralidade presente na história daqueles sujeitos, pode-se abordar e perceber a constituição duma identidade para aquele grupo, imerso em um âmbito urbano. A presença da memória na construção de referências identitárias, tanto no plano interno da coesão intragrupal, que envolve o processo de "sentir-se identificado", quanto no plano das relações intergrupos, que envolvem os processos de inclusão e exclusão, relações históricos sociais construídos e vivenciados, provê de coesão os sentidos e significações da comunidade para seus membros (VALENTIM, 2010, p 281). Assim, a partir dos relatos e histórias contadas, a história oral aproxima e constitui a identidade. A memória se torna uma verdade para a identidade do grupo social - que se identifica com uma narratividade específica.

A comunidade é então atravessada pela busca da identidade, através da necessidade da reconstrução das vivências que representaram os quilombos em um dado momento histórico e cultural, das suas práticas e dos costumes de significar a tradição quilombola. Essa reconstrução é representada principalmente pela manifestação da memória expressa através da herança patrimonial deixada pelas referências da Tia Eva. Após uma leitura compreensiva do conjunto das entrevistas e observações, foi possível estabelecer vínculos criados e sentidos e, posteriormente, estruturas temáticas para a compreensão, interpretação e discussão do tema, buscando a lógica dos relatos e das observações, situando-as no seu contexto social.

Desse modo, em certa medida, pode-se ver que a identidade quilombola foi reforçada a partir da memória social dos descendentes da Tia Eva, residentes da comunidade cujas raízes foram unidas, distinguindo valores costumes e práticas que os assinalam frente a outras culturas, inspirados e espelhados na figura representativa da Tia Eva. Esta identificação foi se moldando a partir da apropriação do grupo pelas atividades de valorização das manifestações tradicionais perpetuadas por meio da história oral e passadas para as novas gerações. Isso ganhou especial densidade a partir da década de 1980, quando os sujeitos passam a se perceber como tais através das movimentações pioneiras de grupos sociais que nasceram em Campo Grande neste período, contaminados pelas intensas movimentações nacionais do final do século XX.

A comunidade Tia Eva ainda está atravessando um período marcante de reconstrução coletiva e transformações na sua caracterização como comunidade quilombola e 
afrodescendente, marcada pelas lutas políticas e afirmação cultural do momento no Brasil. Observamos que não houve um trabalho de conscientização continuo durante o século XX. Em um primeiro momento, a impressão que se tem é de que eles experimentam mas não tem toda a densidade reflexiva desta identidade. Infelizmente, a um certo ponto, atingidos pelas ondas de especulação imobiliária, alguns se desfizeram de seus terrenos e foram embora para outras regiões, o que denota um problema com a consciência identitária. Hoje esta visão anda mudando, apesar da carência e da falta de poder aquisitivo para pagar impostos, por exemplo.

Uma instituição característica da comunidade Quilombola Tia Eva é a presença das frequentes reuniões, realizadas pela Associação de Moradores. Essa Associação dá origem a diversos outros grupos que, unidos, realizam o esforço de ressignificar e assegurar seus costumes e história de arrojamento na consolidação de sua identidade perante a sociedade. Matos (2004, p. 35) colhe esse momento de especial densidade:

Em 15 de maio de 1997, foi registrada em Cartório uma entidade civil sem fins lucrativos, que presta serviços sociais aos seus associados. A sua direção na época, foi constituída por: Sérgio Antônio da Silva (presidente); Eurides Antônio da Silva ( $1^{\circ}$ vice-presidente); Getúlio Caetano de Barros $\left(2^{\circ}\right.$ vicepresidente); Alaíde Batista da Silva (secretária geral); 36 Sandra Mara Martins dos Santos ( $1^{\mathrm{a}}$ secretária); Rildo Ferreira da Silva (tesoureiro geral).

Esse amálgama comportamental da comunidade Quilombola Tia Eva, da memória à institucionalização da coesão por meio da Entidade beneficente, pode conectar-se ao conceito de fato social de Marcel Mauss (1974), pois os membros da comunidade estão estreitamente conectados entre si, com as suas práticas, com o seu meio e até mesmo nas relações com suas próprias raízes. A memória constrói a identidade (as danças e as festas), os momentos de celebração (os festejos e seminários culturais) e os momentos de reconstrução perpassam a dimensão da necessidade e de identificação do grupo.

Os idosos encontram -se nas suas histórias recontadas e vividas principalmente nos rituais da festa do padroeiro São Benedito, motivo que atraiu a Tia Eva para a região, em promessa ao Santo. Suas lembranças aparecem conectadas aos gestos e sons. “(...) participo sim de todos os festejos, é bom demais relembrar né, só não danço mais, mas venho no terço todas as noites (Entrevista da idosa V., 72 anos). 
Já os mais jovens, acreditam na possibilidade do "resgate" das performances para a valorização de seu povo. "Eu acho que é de uma forma, pra seguir a tradição né, porque querendo ou não, um dia eles se vão e aí é bom manter a tradição de há muito tempo atrás." (Entrevista de adolescente K., 21 anos).

A festa em honra de São Benedito surgiu para comemorar a reforma da igreja. Com duração de nove dias, uma novena, com reza, terço, muita música, dança, comida, bebida, e três fogos ao subir a bandeira do santo no alto do mastro, na hora da oração do "Salve Rainha”. Esta história foi contada por um dos descendentes a Vanda Moraes, registrado no livro Tia Eva, Negraeva - história da comunidade São Benedito (2003). Nesta ocasião Eva Maria de Jesus promete a realização da homenagem, enquanto ali houvesse um descendente seu. Percebe-se, ao percorrer os relatos, como se fortalecem as tradições religiosas cristãs advindas da escolha feita pela "missionária" Tia Eva, aos seus descendentes. Porém, não podemos esquecer que o Santo São Benedito foi escolhido como padroeiro, também por ter sido um missionário franciscano negro, um "santo que foi um simples cozinheiro". Isso possibilitou uma série de identificações, além de tecer identidades e laços pelas semelhanças étnicas e sócio-culturais, fortalecendo a aliança com a Comunidade local. A festa do santo faz parte, junto de outras ações educativas desenvolvidas pela Associação, do movimento de afirmação das identidades afrodescendentes, que ganham força na comunidade, (CERUTTI; VIRUEZ, 2015, p.8). Uma motivação contagiante e uma expressão de orgulho pra eles.

Outra ferramenta importante de integração são as reuniões esportivas. É possível observar a importância dos torneios de futebol para a comunidade. Eles são realizados com times de dentro e fora da comunidade, acontecendo de forma regular ao longo do ano e no período da Festa de São Benedito. Durante a festa acontece a mais antiga e tradicional das competições de futebol, o Torneio Tia Eva. Segundo o Sr. Michel, antigo membro da comunidade, a ideia começou há muito tempo, pois a comunidade sempre gostou desse tipo de lazer.

Anteriormente o campinho localizava-se em frente à igreja, e durante a festa de São Benedito o movimento trazido pelo Torneio sempre foi bem vindo. A ideia foi crescendo e por meio de várias reuniões com membros da associação de moradores, presidentes de outras comunidades quilombolas, times de outros bairros não quilombolas, os moradores foram 
procurando pensar em algo diferente do que acontece nos campeonatos do município de Campo Grande, por exemplo. Algo que fosse específico, voltado para a história da comunidade, em ligação com a tradição da festa. Dessa forma, pensaram em escolher um nome para o Torneio de futebol, o de "Tia Eva", com o processo de integração dos times sendo também aproveitado para angariar fundos para a Comunidade.

A coordenação desse torneio sempre vislumbrou a valorização da integração das comunidades quilombolas da região, pois compreende que o futebol é uma festa bastante difundida que tem o condão de aproximar os grupos. Assim, unificaria também a identidade quilombola destes descendentes. É fácil notar que os torneios da comunidade funcionam como dispositivo de fabricação de visibilidade e de consciência, pois chamam a atenção dos participantes para a comunidade e suas questões. Outra questão levantada, é a crença da organização que o poder público, notando os torneios, notaria também que precisa contribuir, diante das tensões em que vive a comunidade. O Torneio é importante e tradicional; entrega sempre o mesmo troféu, que é respeitado como um símbolo entre os times participantes. É preciso que um time ganhe o torneio por três vezes consecutivas pra levá-lo como símbolo da vitória e da honra da participação. A Comunidade tem dois times que a representam.

Ficamos uns anos sem local, quando o inventário foi feito ficamos sem local. Mas nunca deixamos de fazer o campeonato, chegamos a realizar no São Caetano (Bairro próximo). O local do campinho atualmente amplo e estratégico, pois almejamos mais tarde transforma-lo num espaço público e oficial para lazer da comunidade. Mas parte daquele terreno, não pertence mais a comunidade. Infelizmente, uma das primas reunida com irmãos fez a venda sem nosso conhecimento. Odete e Nilton ao se mudarem pra Brasília não viram mais interesse em manter o terreno e com autorização dos irmãos, ela negociou a propriedade. A sorte é que o comprador é amigável e não pretende construir nada. Um pouco antes quase perdemos o espaço, pois ficamos sabendo que estava negociando com uma empresa que queria construir um grande prédio, mas não deu certo. O pedaço também é tombado como quilombola, a ideia é conseguirmos a desapropriação do terreno para construção definitiva da área de lazer. (Sr. Michel, descendente e líder comunitário).

O torneio aparece, ainda, como uma ação coletiva de cunho social, pela qual as comunidades se congregam e, apesar dos problemas no campo da saúde, do saneamento, das estradas, etc., também conseguem mostrar que sabem divertir-se e sorrir. Também nesse 
aspecto é possível ver como a construção da identidade quilombola e a sua visibilidade são ali negociadas ponto a ponto, não vêm dadas nem se essencializam na Comunidade Tia Eva.

Esse morador nos faz entender que o torneio, juntamente com outros movimentos sócio - culturais ao longo do ano, funcionam como um renascer e um grito para o exterior do Quilombo, denunciando que as condições de lazer estão ruins, que os moradores não se sentem vistos com o mesmos olhos que outros cidadãos pelas autoridades públicas, além de sofrerem a ameaça de serem submergidos a qualquer instante por arranha - céus de condomínios projetados por construtoras que apenas especulam, não levam em conta as identidades ou as delicadezas das territorialidades.

É uma forma de sair de um mundo percebido como sendo hostil, eivado de dificuldades, mostrando que podem sorrir, pois estão centrados na celebração de uma cultura e que, por isso, conseguem fazer uma festa, mesmo no seio dessa problemática. É uma forma de dizer que existem, e que necessitam de mais políticas públicas, e que querem ver selecionados os problemas de conflitos com estas empresas e a sociedade. É uma forma ainda de sensibilizar, para engajar os mais jovens no movimento de construção da cidadania e da participação.

É com esse pensamento em vista que a Associação planeja, oferta e promove, em outros torneios e festas, atividades como a capoeira, a venerável dança afrobrasileira; o samba e o pagode; exposições de arte; mostras de cinema além de artesanato, cursos de diversas áreas e outras ações que oportunizam novos encontros, aumento do sentimento de pertença e solidariedade e, talvez o que subjaz a todo o movimento, o vislumbre de horizontes de tecimento do vivido com paz e no respeito à própria densidade histórica. Assim a Comunidade Quilombola Tia Eva, em suas atividades de integração e lazer, esforça-se para espraiar seus saberes para horizontes que ultrapassam a suas aspirações como comunidade quilombola; é através deste movimento sem fronteiras que "burla" o espaço físico e geográfico em que está sediada - e assim, o redesenha.

Dessa forma a comunidade aparece como representante não apenas de um espaço relevante do reconhecimento da identidade quilombola, mas como um coletivo de cidadãos ativos, integrantes de um meio social no seio do município do qual participam. Com isso, é no âmbito da história e da cultura construída socialmente que essas identidades se formam em 
diferentes momentos, deslocam-se e tornam-se provisórias, variáveis e problemáticas, em um processo contínuo de construção e de reconstrução nas interações sociais dos indivíduos e dos grupos sociais em seus espaços físicos híbridos e, portanto, culturais (HALL, 2005, p.12).

As atitudes de negociação celebrada da identidade aparecem, pois, com força crítica, com relação direta com os impactos causados pela presença de influências externas, que denotam uma crise identitária em conflito, e que reage criativamente. As pessoas da comunidade apresentam alguma "timidez", quando indagadas sobre a sua percepção da identidade quilombola na Comunidade Tia Eva. Alegam que estão despreparados pela falta de informações e de conhecimentos do que é ser quilombola, afirmando que essa identidade encontra-se no campo de tensões experimentado na relação com o contexto amplo da sociedade.

Assim, no bojo da discussão em que a Comunidade Tia Eva se configura em ambientes e contextos diversos (com a diversidade cultural em destaque), é fundamental que haja um clima favorável para investir criativamente realizando, fazendo coisas, criando, como meio para reforçar a importância da memória. Com isso os descendentes de Tia Eva analisam a própria função das instituições às quais se apresentam, revelando o racismo estrutural presente na produção do conhecimento e na implementação das relações sociais. Mas é importante notar que essa relação, acontecendo de forma ativa e propositiva, é geradora de identidade e de festa.

\section{Considerações Finais}

As expressões artísticas, religiosas e esportivas da comunidade são ferramentas para a sua negociação identitária. Estão alicerçadas em práticas diárias, passando pelo processo de reconstrução caracterizado, principalmente, pelo esforço sistemático de fomento à participação dos mais jovens na elaboração da negociação ou reformulação identitária. Todo o movimento de construção ao redor da identidade encontra-se centralizado, por sua vez, em torno da personalidade e representatividade histórica e familiar da Tia Eva, que tem sido a principal motivação para esta identificação como comunidade Quilombola. E mesmo com todas as interferências e relações do contexto contemporâneo, com a hostilidade característica 
do meio urbano, os adultos e adolescentes procuram se envolver nas atividades do grupo e da reconstrução da identidade quilombola da comunidade.

Aparece em destaque no imaginário social e cultural da comunidade a força da memória na valorização da imagem dos idosos, enquanto importante elo da tradição quilombola. É possível perceber a influência deles na participação das práticas corporais e culturais do grupo, como elementos chave para despertar o interesse dos jovens para o horizonte dos sentidos das experiências do seu povo. Essa importância é perceptível na oralidade dos sujeitos da comunidade, durante as entrevistas informais, realizadas durante a festa do padroeiro, bem como nas reuniões da Associação de Moradores e Torneios de futebol.

Todas as práticas antigas representadas na comunidade Tia Eva, foram buscadas e desenvolvidas a partir do momento em que esses sujeitos perceberam a necessidade de se afirmarem, em relação com a sociedade em que vivem. Nesse sentido as práticas religiosas formam um importante elo, uma vez que é nelas que encontramos os primeiros elementos que individuaram a singularidade desse grupo e que vieram circundando e permeando todas as outras manifestações e movimentações sociais.

O fortalecimento das relações nos grupos, através do processo de produção das identidades e alteridades, favorece e reforça os vínculos sociais. Os membros adquirem um desejo de união e uma empatia, na qual eles se fortalecem em conjunto, tecendo o corpo social, a partir do prazer de pertencer e criar laços, conferindo-lhes uma dimensão de sentido que transcende os limites do próprio grupo. E para isso, eles usam as festas e celebrações como recurso, mas não a fim de reproduzir o que estava esquecido. Mais que isso, com o objetivo de identificar, reconstruir e evidenciar a tradição quilombola em uma comunidade de caráter urbano, com suas novas determinações e contexto.

A realização de todas estas atividades culturais, sociais e esportivas funcionam para os membros da comunidade como uma expressiva forma de divulgar a cultura afrodescendente, considerando o encontro das diferentes culturas que compõe o Estado de Mato Grosso do Sul.

O dinamismo e a clara inserção espaçotemporal mostram o esforço que a comunidade empreende para realizar ações que a envolvem como um todo, alcançando todas as gerações, ainda promovendo um trabalho que possibilita aos sujeitos uma forma 
diferenciada de se enxergar no contexto atual, como cidadãos atuantes. Assim aparece a questão do negro afrodescendente, como um enigma, quando percebemos que as representações dos símbolos e signos que essas comunidades carregam em sua cultura, com muita frequência são desconsideradas ou apresentadas de forma estereotipada, embracados em ações que corroem os esforços de construção da identidade - e portanto, reafirmando a cultura dominante. Assim, o que se pode observar como movimento geral a partir destas reflexões, é que a comunidade possui dinamismo interior e esforço institucionalizado para dialogar com os novos sujeitos emergentes, que ainda se encontram em crise e em fase de formação. As questões referentes à constituição das identidades culturais nos ambientes encontram-se em contínua construção e constituem terreno fértil para a exploração, mediante pesquisas acadêmicas, como forma de repensar o papel do negro diante dessa nova sociedade do século XXI. Mais ainda, como forma de a academia perceber que ali o negro está repensando o seu "ser" e o seu papel.

\section{Referências}

ALVAREZ, G. O.; BORELA, H. A.; MARTINS, T. R. Tradição cultural e práticas corporais em comunidades quilombolas de Goiás: notas para uma política de esporte e lazer. Goiânia: Editora PUC Goiás, 2011.

ARRUTI, J. M. A emergência dos " remanescentes": notas para o diálogo entre indígenas e quilombolas. Mana v. 3, n.2, p. 7-38, 2007

BAUMAN, Zygmunt. Identidade. Tradução de Carlos Alberto Medeiros. Rio de Janeiro:Jorge Zahar Editor, 2005.

BOSI, A. Dialética da colonização. Cultura brasileira e culturas brasileiras. São Paulo: Companhia das Letras, 1991.

CERUTTI, Aline. VIRUEZ, Nelly S. C. Festa de São Benedito na Comunidade Quilombola tia Eva: frestas para pensar as identidades afro- brasileiras. CONFAEB, 2015.

CHAUÍ, Marilena. Convite à Filosofia. Ed. Ática, São Paulo, 2000.

Fronteiras: Revista de História | Dourados, MS | v. 19 | n. 33 |p. 147 - 169 | Jan. / Jun. 2017 
DESLANDES, S. F. Pesquisa social: teoria, método e criatividade. In: MINAYO, Maria Cecilia de Souza (org.). 29 ed. Petropolis, Rio de Janeiro: Vozes, 2010.

EAGLETON, Terry. A ideia de Cultura. Tradução de Sofia Rodrigues. Oxford: Blackwell Publishers Limited, 2000.

FALCÃO, J. C.; INÁCIO, H. L e VIEIRA, L. R. De quilombos e quilombolas: aspectos legais e debate legislativo. Goiânia: Ed. Da PUC Goiás, 2011.

GILROY, Paul. "Uma História para não se Passar Adiante": A Memória Viva e o Sublime Escravo. In: O Atlântico Negro. Tradução de Cid Knipel Moreira. São Paulo: Editora 34/UCAM, 2001. p. 351-416.

GUIMARÃES, Antonio Sérgio Alfredo. Racismo e Anti-Racismo no Brasil. São Paulo: Editora 34, 1999.

HALL, Stuart. A identidade cultural na pós-modermidade. Tradução de Tomaz Tadeu da Silva e Guacira Lopes Louro. 10. ed. Rio de Janeiro: DP\&A, 2005.

MATOS, Eliane, Comunidade São Benedito, Campo Grande - MS: Patrimônio Cultural, Turismo e Desenvolvimento Local. 2004. 95 p. Dissertação (Mestrado em Desenvolvimento Local) - Programa de Pós-Graduação em Desenvolvimento Local, Universidade Católica Dom Bosco

SANTOS, Carlos Alexandre B. Plínio dos «Eva Maria de Jesus (tia Eva) », Anuário Antropológico [Online], I | 2012, posto online no dia 01 Outubro 2013, consultado no dia 14 Março 2017. URL : <http://aa.revues.org/317 ; DOI : 10.4000/aa.317>

SANSONE, Livio. Negritude sem Etnocidade. Salvador: Edição UFBA. Tradução: Vera Ribeiro, 2004.

SALEM, Terezinha de Alencar. 100 mulheres pioneiras de Campo Grande, 100 anos de Campo Grande. BPWCG, Campo Grande, 1999.

VALENTIM, R.; TRINDADE, Z. A. e MENANDRO, M. C. S., Memórias sociais de juventude entre quilombolas do norte do Espírito Santo. Revista Psicologia e Sociedade. vol.22, n.2, p.279-287, 2010. 